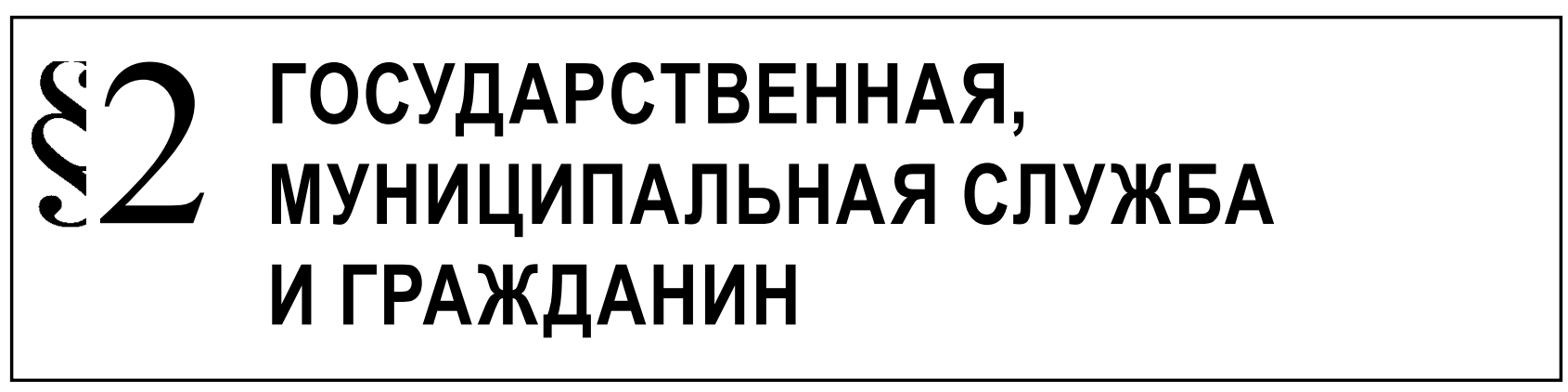

Митрохин В.В.

\title{
СЛУЖБА В ОРГАНАХ ВНУТРЕННИХ ДЕЛ КАК РАЗНОВИДНОСТЬ ФЕДЕРАЛЬНОЙ ГОСУДАРСТВЕННОЙ ПРАВООХРАНИТЕЛЬНОЙ СЛУЖБЫ
}

\begin{abstract}
Аннотация: Исходя из предмета статьи, в ней отмечается, что формирование современной и эфрфективной государственной службы Российского государства относится к приоритетным направлениям преобразований, происходящих в административно-политической срере государственного управления. Как следует из объекта нашего исследования в настоящее время организация государственной службы в системе МВД России, а также ее кадровая основа находятся не в лучшем состоянии, и не соответствует целям и задачам социальноэкономического развития страны. Последствия проявляются практически во всех срерах жизни: в экономике, финансовой деятельности, в решении социальных вопросов, в науке и культуре, внутренней, межнациональной и международной политике, обороне и безопасности. Именно на представленных основах строиться наше исследование. Методологическую основу статьи составили современные достижения теории познания. В процессе исследования применялись теоретический, общефилософские методы (диалектика, системный метод, анализ, синтез, аналогия, дедукция, наблюдение, моделирование), традиционно правовые методы (формально-логический), а также методы, используемые в конкретно-социологических исследованиях (статистические, экспертные оценки и др.). Государственная служба вообще и служба в органах внутренних дел в частности, это необходимый атрибут современного российского государства. Государственная служба, каких бы видов она не была, а также в каких бы формах не реализовывалась, всегда направлена на осуществление государственной политики, а также применение тех функций, которые, собственно, и закреплены за государством. Поэтому, государственная служба как публично-правовой институт находится в непосредственной диалектической связи с государством и, как следствие этого, занимает промежу-точное звено между гражданином и должностным лицом, которое осуществляет те или иные государственные полномочия.
\end{abstract}

Ключевые слова: служба, служащий, чиновник, МВД, полиция, ОВД, контракт, права, обязанности, государство. Review: The author states that the formation of a modern and effective public service of the Russian state is one of priority directions of reforms taking place in administrative and political sphere of public service. At present the organization of public service within the system of Internal Affairs of the Russian Federation and its personnel policy don't meet the requirements of socio-economic development of the country. The consequences can be seen almost in all spheres of life: in economics, financial activities, social sphere, science and culture, in internal and international affairs, defense and security. The research is based on the presented grounds. The methodology of the research is based on the modern achievements of epistemology. The author uses the theoretical and general philosophical methods (dialectics, the system method, analysis, synthesis, analogy, deduction, observation, and modeling), the traditional legal methods (formal-logical), and the methods used in special sociological research (the statistical method, expert evaluations, etc.). Public service in general and service in the bodies of internal affairs in particular, is an essential element of the modern Russian state. Public service of any kinds and forms is always aimed at implementation of the state policy and the state functions. Therefore, public service as a political institution is directly dialectically connected with the state and, thus, is an interim link between a citizen and a public servant implementing any state functions.

Keywords: service, servant, official, Ministry of Internal Affairs, police, bodies of internal affairs, contract, rights, responsibilities, state. 
$\mathrm{H}$ а каждом этапе государственного строительства наша страна сталкивается с самыми различными трудностями и противоречиями социально-экономического развития, которые требуют своего кардинального реагирования. Решение целого ряда проблем в вопросах модернизации системы публичного управления возможно лишь при условии формирования честного и компетентного корпуса государственных служащих. Как показывает опыт государственного строительства, центральное место в организации служебных отношений принадлежит сотрудникам правоохранительных органов, а если быть точнее, сотрудникам органов внутренних дел. В этой связи представить себе современную государственную службу Российской Федерации без правоохранительной службы Российской Федерации практически невозможно.

Исходя из этого, государственная служба вообще и служба в органах внутренних дел в частности, это необходимый атрибут современного российского государства. Государственная служба, каких бы видов она не была, а также в каких бы формах не реализовывалась, всегда направлена на осуществление государственной политики, а также применение тех функций, которые, собственно, и закреплены за государством. Поэтому, государственная служба как публично-правовой институт находится в непосредственной диалектической связи с государством и, как следствие этого, занимает промежуточное звено между гражданином и должностным лицом, которое осуществляет те или иные государственные полномочия. Необходимо сказать, что государственная служба, как публично-правовое образование, является предметом изучения различных научных дисциплин, у каждой из которых свой предмет в исследовании и понимании соответствующего феномена.

Несмотря на то, что государственная служба изучается в различных аспектах, тем не менее, наиболее предметно соответствующий институт исследован именно в области права, а если быть более точным, рассматриваемое образование весьма предметно изучается именно в науке административного права. Как верно отмечает А.А. Гришковец, «...государственная служба - один из важнейших, фундаментальных институтов административного права» ${ }^{1}$.

В этой связи бесспорен тот факт, что административное право занимает центральное место 1 См.: Гришковец А.А. Государственная гражданская служ-
ба. - М., 2014. - С. 8. в механизме правового регулирования государственно-служебных отношений, однако надо признать, что и другие отрасли российского права также касаются обозначенного предмета правового воздействия.

В частности, Конституция Российской Федерации задает вектор в развитии законодательства о государственной службе, в этом документе отмечается, что граждане Российской Федерации имеют равный доступ к государственной службе (п. 4 ст. 32), а также то, что федеральная государственная служба находится в ведении Российской Федерации (п. т ст. 71). Как первое, так и второе предписание Конституции нашей страны имеют самое непосредственное отношение к правовому регулированию, а также и к организации государственной службы осуществляемой в системе МВД России. Государственная служба как публичноправовое образование представляет собой иерархически выстроенный институт, который обладает рядом сущностных признаков, на которые будет обращено внимание чуть ниже.

Государственная служба - это место где гражданин может реализовать свою трудовую правосубъектность, а если сказать иными словами свои способности в сфере труда. Кроме того, государственная служба обладает властным потенциалом, в связи с чем прохождение службы осуществляется в установленном правовом режиме, предполагающем ее особый статус и функциональный потенциал. Государственную службу реализует определенная категория специально подготовленных людей, которые имеют статус государственных служащих. Все эти, а также ряд иных признаков качественно отличают государственную службу от иных видов социально-полезной и трудовой деятельности людей. Необходимо отметить, что цель нашего исследования не стоит в рассмотрении всего института государственной службы, наша задача затронуть лишь один сегмент соответствующего образования, на который содержится указание в названии настоящей работы. Исходя из этого, нужно заметить, что служба в органах внутренних дел соотносится с институтом государственной службы как часть к целому.

Поэтому, в силу объективных обстоятельств, она обладает определенным качественным своеобразием, а также функциональным предназначением, тем не менее, некоторые общие признаки государственной службы все же присущи службе, осуществляемой в органах внутренних дел. Об особенностях службы в органах и организациях системы МВД России будет отмечено также несколь- 
ко ниже, а сейчас представляется необходимым сказать в целом о понимании института государственной службы в российском праве, которое сложилось к настоящему времени в юридической литературе. Такой подход позволит системно подойти к определению сущностных признаков службы, осуществляемой в органах внутренних дел. Более того, государственная служба, осуществляемая в системе МВД России в целом, не может развиваться автономно без взаимодействия с иными видами государственной службы. На данный факт обратил также внимание П.П. Сергун, который подчеркнул, что государственную службу в органах внутренних дел нельзя рассматривать как некую оторванную, абсолютно самостоятельную категорию от общего развития государственной службы Российской Федерации. При этом цитируемый автор отмечает, что если государственную службу определить в качестве родового объекта, то государственная служба в органах внутренних дел будет выступать как разновидность родового объекта, а именно видовым объектом»². Именно обозначенный методологический подход следует использовать при исследовании службы в органах внутренних дел, как разновидности федеральной государственной правоохранительной службы. Для подкрепления высказанного суждения представляется необходимым обратиться к теоретическому анализу института государственной службы.

Заметим, что институт государственной службы получил достаточное содержательное теоретическое обоснование еще в XIX в. В частности, в этот период обозначенный феномен исследовался весьма содержательно. Так, А. Яновский под государственной службой понимал отношение к государству лиц, которым поручалось исполнение государственной должности, то есть обязанности постоянной деятельности по достижению определенных целей государства, для чего служащие наделялись необходимыми полномочиями и правами ${ }^{3}$.

В этом определении, в целом, сделан верный акцент на базовые компоненты государственной службы, а именно - автором указывается на необходимость замещения соответствующим лицом определенной должности, кроме того, государственная

\footnotetext{
2 См.: Сергун П.П. Государственная служба в органах внутренних дел Российской Федерации: состояние и теория развития. - Саратов, 1998. - С. 50.

3 См.: Яновский А. Государственная служба // Энциклопедический словарь. Изд. Ф.А. Брокгауз, И.А. Эфрон - М., 1893. T. 9. - С. 392.
}

служба увязывалась с целями деятельности государства, к выполнению которых обязан стремиться служащий, наделенный необходимой компетенцией.

Указание на необходимость замещения определенной должности в системе государственной службы мы находим и у видного государствоведа того периода А.Д. Градовского, который, также исследуя обозначенный институт, отмечал, что «... государственная служба - это известное юридическое отношение, возникающее для данного лица, вследствие принятия им определенной государственной должности» ${ }^{4}$.

Весьма абстрактно к определению государственной службы в свое время подошел В.В. Ивановский. В частности, он видел в государственной службе свободный договор, из которого вытекает одностороннее публично-обязательственное отношение частных лиц к носителю верховной власти, ради осуществления воли последнего ${ }^{5}$.

C таким подходом к определению государственной службы с позиции сегодняшнего дня вряд ли можно согласиться, поскольку государственная служба вообще и осуществляемая в органах и организациях системы МВД России в частности, не может быть рассмотрена как одностороннее обязательство, государственная служба - это определенное правоотношение со взаимными правами и обязанностями соответствующих сторон, в нашем - случае государства, в лице Министерства внутренних дел Российской Федерации и гражданина, который замещает определенную должность в соответствующей системе.

Наиболее современное определение государственной службы, которое было сформулировано в XIX в. принадлежит О. Эйхельману. В частности, он отмечал, что государственная служба «...есть исполнение лицом, по собственному его согласию и по назначению правительственной властью, постоянной должности, по штату или сверх штата, с определенными обязанностями в учреждениях государственного управления и служебной ответственностью, соединенное с получением жалованья, выслугой чинов, знаков отличия и пенсии» ${ }^{6}$.

\footnotetext{
4 См.: Градовский А.Д. Общие качества служебной деятельности // Начала русского государственного права. - СПб., 1897. - С. 231.

5 См.: Ивановский В.В. Русское государственное право. Государственная служба. - Казань, 1895. Вып. 7. - С. 121.

6 См.: Эйхельман О. Обзор центральных и местных учреждений управления в России и Устава о службе по определению от правительства. - Киев, 1890. - С. 76.
} 
Как мы видим, в этом определении указывается не только на необходимость замещения должности, которая предоставляет некий служебный правовой статус лицу, но и на целый ряд социальных гарантий, содержание которых является важным моментом, как в тот период, так и в настоящее время.

В советский и российский период нашей истории государственная служба в исследовательском аспекте также обращала на себя внимание. Так, С.С. Студеникин констатировал, что «...государственная служба - это отношение того или иного лица к государству, в силу которого это лицо получает полномочия осуществлять в той или иной форме государственные функции» ${ }^{7}$. Приведенное определение во многом носило типичный характер для советского периода нашей истории. В определении государственной службы традиционно указывалось на выполнение лицом, замещающим какую либо должность в государственном аппарате тех или иных государственных функций. На содержание научных исследований института государственной службы, проводимых в советский период нашей истории, налагало свой отпечаток и то обстоятельство, что в этот период времени так и не было создано специального законодательства, комплексно регламентирующего служебные отношения в государственном аппарате, исключение составляла лишь милитаризированная государственная служба. Одним из первых документов советской власти в этом аспекте, который был призван регламентировать службу в милиции - являлся Декрет ВЦИК, СНК РСФСР от 10 июня 1920 г. «О Рабочее - Крестьянской Милиции (Положение)» ${ }^{8}$.

Согласно § 6 обозначенного акта, на службу в милицию могли быть приняты лица, которые достигли 21 года, грамотные, пользующиеся избирательным правом, не состоящие под следствием и судом по обвинению в преступлениях, а также вполне здоровые и пригодные для службы. Как можно судить из обозначенных предписаний (требований), на службу в милицию могли быть приняты далеко не все желающие. Тенденция регламентировать службу в органах внутренних дел в специальных нормативных правовых актах получила свое продолжение и в дальнейшем.

В новейшей истории государственная служба также нашла свое теоретическое обоснование. Исследования, которые проводились в 90-е годы

\footnotetext{
7 См.:Студеникин С.С.Советская государственная служба// Вопросы административного и военно-административного права. - М., 1948. - С. 3.
}

8 СУ РСФСР. - 1920. - № 79. - Ст. 371.
XX в. преимущественно опираясь на предписания Федерального закона от 31 июля 1995 г. «Об основах государственной службы Российской Федерации»9. Такой подход был во многом продиктован тем, что это был первый законодательный акт, который регламентировал отношения в системе государственной службы с публично-правовой точки зрения.

С учетом законодательства о государственной службе Российской Федерации, А.Ф. Ноздрачев писал, что «...государственная служба, как вид профессиональной деятельности означает непрерывное, преемственное и компетентное обеспечение исполнения полномочий государственных органов лицами, находящимися на государственных должностях. Кроме того, государственная служба - это профессия для государственных служащих, которая требует специальной подготовки, получения специального образования, поэтому они принимаются на постоянную работу, им присваиваются квалификационные разряды, звания, ранги ${ }^{10}$.

В таком понимании государственной службы находят свое отражения сущностные признаки соответствующего института, которые характеризуют его как профессиональное, а также целостное публично-правовое образование.

В ходе реформирования государственной службы, в начале 2000-х годов был принят Федеральный закон от 27 мая 2003 г. «0 системе государственной службы Российской Федерации» ${ }^{11}$, который определил, что система государственной службы включает в себя следующие виды государственной службы: государственная гражданская служба; военная служба; правоохранительная служба (ст. 2). Все эти виды государственной службы между собой, так или иначе, логически взаимосвязаны, поскольку каждый из них позволяет государству реализовывать поставленные перед ним задачи и функции в соответствующей сфере. Исходя из предмета исследования, наибольшей интерес для нас представляет институт правоохранительной службы, поскольку именно в его содержании функционирует государственная служба, осуществляемая в органах и организациях системы МВД России.

Согласно законодательству, правоохранительная служба - это вид федеральной государ-

9 Собрание законодательства РФ. - 1995. - № 31. - Ст. 2990.

10 См.: Ноздрачев А.Ф. Государственная служба. - М., 1999. C. 37.

11 Собрание законодательства РФ. - 2003. - № 22. - Ст. 2063. 
ственной службы, представляющей собой профессиональную служебную деятельность граждан на должностях правоохранительной службы в государственных органах, службах и учреждениях, осуществляющих функции по обеспечению безопасности, законности и правопорядка, по борьбе с преступностью, по защите прав и свобод человека и гражданина. Таким гражданам присваиваются специальные звания и классные чины. Исходя из своего содержания, служба в органах внутренних дел, является правоохранительной службой.

Необходимо сказать, что несмотря на то, что сотрудники полиции, а также иные сотрудники МВД России выполняют задачи по защите прав и свобод граждан, осуществляют комплекс мер по противодействию преступлениям и административным правонарушениям, Федеральный закон от 30 ноября 2011 г. «0 службе в органах внутренних дел Российской Федерации» ${ }^{12}$ специально не акцентирует внимание на правоохранительном аспекте службы в органах и организациях системы МВД России. В частности, обозначенный закон определяет, что служба в органах внутренних дел - это федеральная государственная служба, представляющая собой профессиональную служебную деятельность граждан Российской Федерации на должностях в органах внутренних дел Российской Федерации, а также на должностях, не являющихся должностями в органах внутренних дел (ст. 1). Такой подход, как нам представляется, далеко не в полной мере соответствует содержательному аспекту служебной деятельности, которая осуществляется в сфере внутренних дел. В представленном определении акцент должен быть сделан на том, что эта служба носит правоохранительный характер.

В этой связи рассмотрим ряд теоретических положений, которые характеризуют правоохранительную службу в целом, и службу в органах внутренних дел, в частности. Вопрос о правоохранительной службе тесно связан с такими категориями, как «правоохранительный орган», «правоохрана», «правоохранительная деятельность». Провиденные категории в действующем законодательстве не раскрываются. Между тем вполне оправдан вывод о том, что правоохранительные органы занимают особое место в деятельности государственного аппарата, их работа направлена на реализацию различных правоохранительных средств, цель которых обеспечить правопорядок, а также защиту прав и свобод граждан.

12 Собрание законодательства РФ. - 2011. - № 49 (ч. 1). - Ст. 7020 .
Именно из этого исходят определения правоохранительной службы, которые сформулированы в настоящее время в юридической литературе.

В частности, А.М. Артемьев, давая характеристику правоохранительной службе, указывает на ее как форму государственной деятельности ${ }^{13}$. С таким подходом следует согласиться, поскольку между правоохранительной службой и службой в органах внутренних дел имеет место логическая взаимосвязь общего и особенного. Исходя из этого, можно сделать вывод о том, что правоохранительная служба является формой для реализации службы в органах внутренних дел. В ряде исследований правоохранительная служба определяется через правоохранительную деятельность ${ }^{14}$. Однако, несмотря на различные подходы в вопросах понимания правоохранительной службы, все же наиболее принципиальным вопросом является отнесение службы в органах внутренних дел к федеральной правоохранительной службе. На этот аспект службы в органах внутренних дел также обращалось внимание в научной литературе. В частности, В.В. Касюлин и Ю.В. Кивич отмечают, что служба в органах внутренних дел является разновидностью федеральной государственной службы, которая осуществляется на должностях рядового и начальствующего состава на всей территории страны через созданные территориальные органы ${ }^{15}$.

Исходя из этого положения, Е.В. Позднякова под государственной службой в органах внутренних дел, предлагает понимает урегулированную нормами права служебную деятельность граждан Российской Федерации, осуществляемую на профессиональной основе за соответствующее вознаграждение, направленную на реализацию задач и функций, стоящих перед органами внутренних дел, посредством замещения должностей правоохранительной службы, учрежденных в органах внутренних дел, характеризуемую определенным административно-правовым статусом сотрудников ${ }^{16}$.

\footnotetext{
13 См.: Артемьев А.М. Государственная правоохранительная служба: системные свойства, функции, правовое обеспечение: Автореф. дис. ... д-ра юрид. наук. - М., 2008. - С. 18.

14 См.: Патрашко Е.Л. Государственная правоохранительная служба Российской Федерации: Дис. ... канд. юрид. наук. - M., 2005.

15 См.: Касюлин В.В., Кивич Ю.В. Государственная служба в органах внутренних дел. - М., 2003. - С. 8.

16 См.: Позднякова Е.В. Правовое регулирование прохождения государственной службы в органах внутренних дел Российской Федерации: Автореф. дис. ... канд. юрид. наук. - Воронеж, 2010. - C. 8.
} 
В приведенных определениях службы в органах внутренних дел, акцентируется внимание на необходимости замещения лицом должности в органах и организациях системы МВД России. Кроме того, служебная деятельность в органах внутренних дал напрямую перекликается с реализацией тех задач и функций, которые стоят перед МВД России. Помимо всего прочего, служба в органах внутренних дел связана с реализацией тех задач, которые прямо вытекают из Федерального закона от 7 февраля 2011 г. «0 полиции» ${ }^{17}$.

Подводя итог вышесказанному, следует отметить, что служба в органах внутренних дел является федеральной государственной службой, которая осуществляется на должностях созданных в органах и организациях системы МВД России сотрудниками, которые назначены на соответствующие должности и которым присваиваются специальные звания.

Служба в органах внутренних дел носит профессиональный характер, в связи с этим к сотрудникам, которые претендуют на замещение соответствующих должностей, предъявляются определенные требования к уровню их профессионального образования. В настоящее время для замещения большинства должностей в системе государственной службы, осуществляемой в органах внутренних дел, необходимо наличие высшего юридического образования. Помимо специальных званий, сотрудникам органов внутренних дел при сдаче соответствующих экзаменов может быть присвоена классность. В отличие от государственной гражданской службы - сотрудники, проходящие службу в органах внутренних дел, имеют льготное исчисление выслуги лет, а также более высокое социальное обеспечение, нежели государ- ственные гражданские служащие. Также необходимо сказать, что для организации прохождения службы в органах внутренних дел характерны элементы воинской дисциплины, а также некоторый риск, обусловленный характером выполняемых задач по обеспечению правопорядка, а также защиты прав и свобод граждан. Законодательством установлены и иные характерные особенности для государственной службы, осуществляемой в системе МВД России. Тем не менее, в организации и правовом регулировании государственно-служебных отношений существуют общие обязанности и требования, в частности, касающиеся противодействия коррупции. На сотрудника органов внутренних дел в полном объеме возлагаются те же обязанности, запреты и ограничения, которые связанны с противодействием коррупции, так же, как и на государственных гражданских служащих. Кроме того, в системе государственной службы установлены единые этические стандарты служебного поведения, которые касаются как гражданских служащих, так и сотрудников органов внутренних дел.

В завершении рассмотрения особенностей государственной службы в органах внутренних дел необходимо отметить, что для этого вида государственной службы характерна весьма существенная централизация в вопросах правового регулирования прохождения службы, более высокие требования, касающиеся морально-психологической и физической подготовки сотрудника, кроме того, в сфере внутренних дел установлен более жесткий режим служебной дисциплины. Все эти, а также ряд иных особенностей качественно отличают службу в органах внутренних дел от иных видов служебной деятельности, осуществляемой в государственном аппарате.

\section{Библиография:}

1. Артемьев А.М. Государственная правоохранительная служба: сис-темные свойства, функции, правовое обеспечение: Автореф. дис. ... д-ра юрид. наук. - М., 2008.

2. Гришковец А.А. Государственная гражданская служба. - М., 2014.

3. Сергун П.П. Государственная служба в органах внутренних дел Рос-сийской Федерации: состояние и теория развития. - Саратов, 1998.

4. Градовский А.Д. Общие качества служебной деятельности // Начала русского государственного права. - СПб., 1897.

5. Ивановский В.В. Русское государственное право. Государственная служба. - Казань, 1895. Вып. 7.

6. Касюлин В.В., Кивич Ю.В. Государственная служба в органах внут-ренних дел. - М., 2003.

7. Ноздрачев А.Ф. Государственная служба. - М., 1999.

8. Патрашко Е.Л. Государственная правоохранительная служба Российской Федерации: Дис. ... канд. юрид. наук. М., 2005.

9. Позднякова Е.В. Правовое регулирование прохождения государст-венной службы в органах внутренних дел Российской Федерации: Автореф. дис. ... канд. юрид. наук. - Воронеж, 2010.

17 Собрание законодательства РФ. - 2011. - № 7. - Ст. 900. 
10. Студеникин С.С. Советская государственная служба // Вопросы административного и военно-административного права. - М., 1948.

11. Эйхельман О. Обзор центральных и местных учреждений управле-ния в России и Устава о службе по определению от правительства. - Киев, 1890.

12. Яновский А. Государственная служба // Энциклопедический сло-варь. Изд. Ф.А. Брокгауз, И.А. Эфрон - М., 1893. Т. 9.

13. Костенников М.В., Куракин А.В. Административно-правовое противодействие коррупции в системе государственной службы и в деятельности сотрудников полиции Российской Федерации и зарубежных государств. // Полицейская деятельность.-2011.-1.-С. 10-16.

14. М.В. Костенников, А.В. Куракин, И.Н. Кошелев Административно-правовое регулирование обеспечения собственной безопасности и противодействия коррупции в органах внутренних дел (ч. 2). // Административное и муниципальное право.-2011.-2.-С. 38-45.

15. Костенников М.В., Куракин А.В., Кошелев И.Н. Административно-правовое регулирование обеспечения собственной безопасности и противодействия коррупции в органах внутренних дел (ч. 3 окончание начало в № 1 , 2 - 2011 г.) // Административное и муниципальное право.-2011.-4.-С. 52-61.

16. Куракин А.В., Костенников М.В. Административно-правовое противодействие коррупции в системе государственной службы и в деятельности сотрудников полиции Российской Федерации и зарубежных государств // NB: Российское полицейское право.-2013.-1.-C. 65-83. DOI: 10.7256/2306-4218.2013.1.735. URL: http://www.enotabene.ru/pm/article_735.html

\section{References (transliterated):}

1. Artem'ev A.M. Gosudarstvennaya pravookhranitel'naya sluzhba: sis-temnye svoistva, funktsii, pravovoe obespechenie: Avtoref. dis. ... d-ra yurid. nauk. - M., 2008.

2. Grishkovets A.A. Gosudarstvennaya grazhdanskaya sluzhba. - M., 2014.

3. Sergun P.P. Gosudarstvennaya sluzhba v organakh vnutrennikh del Ros-siiskoi Federatsii: sostoyanie i teoriya razvitiya. Saratov, 1998.

4. Gradovskii A.D. Obshchie kachestva sluzhebnoi deyatel'nosti // Nachala russkogo gosudarstvennogo prava. - SPb., 1897.

5. Ivanovskii V.V. Russkoe gosudarstvennoe pravo. Gosudarstvennaya sluzhba. - Kazan', 1895. Vyp. 7.

6. Kasyulin V.V., Kivich Yu.V. Gosudarstvennaya sluzhba v organakh vnut-rennikh del. - M., 2003.

7. Nozdrachev A.F. Gosudarstvennaya sluzhba. - M., 1999.

8. Patpashko E.L. Gosudarstvennaya pravookhranitel'naya sluzhba Rossiiskoi Federatsii: Dis. ... kand. yurid. nauk. - M., 2005.

9. Pozdnyakova E.V. Pravovoe regulirovanie prokhozhdeniya gosudarst-vennoi sluzhby v organakh vnutrennikh del Rossiiskoi Federatsii: Avtoref. dis. ... kand. yurid. nauk. - Voronezh, 2010.

10. Studenikin S.S. Sovetskaya gosudarstvennaya sluzhba // Voprosy administrativnogo i voenno-administrativnogo prava. M., 1948.

11. Eikhel'man 0. Obzor tsentral'nykh i mestnykh uchrezhdenii upravle-niya v Rossii i Ustava o sluzhbe po opredeleniyu ot pravitel'stva. - Kiev, 1890.

12. Yanovskii A. Gosudarstvennaya sluzhba // Entsiklopedicheskii slo-var'. Izd. F.A. Brokgauz, I.A. Efron - M., 1893. T. 9.

13. Kostennikov M.V., Kurakin A.V. Administrativno-pravovoe protivodeistvie korruptsii v sisteme gosudarstvennoi sluzhby i v deyatel'nosti sotrudnikov politsii Rossiiskoi Federatsii i zarubezhnykh gosudarstv. // Politseiskaya deyatel'nost'.-2011.1.-C. 10-16.

14. M.V. Kostennikov, A.V. Kurakin, I.N. Koshelev Administrativno-pravovoe regulirovanie obespecheniya sobstvennoi bezopasnosti i protivodeistviya korruptsii v organakh vnutrennikh del (ch. 2). // Administrativnoe i munitsipal'noe pravo.-2011.-2.-C. 38-45.

15. Kostennikov M.V., Kurakin A.V., Koshelev I.N. Administrativno-pravovoe regulirovanie obespecheniya sobstvennoi bezopasnosti i protivodeistviya korruptsii v organakh vnutrennikh del (ch. 3 okonchanie nachalo v № 1 , 2 - 2011 g.) // Administrativnoe i munitsipal'noe pravo.-2011.-4.-C. 52-61.

16. Kurakin A.V., Kostennikov M.V. Administrativno-pravovoe protivodeistvie korruptsii v sisteme gosudarstvennoi sluzhby i v deyatel'nosti sotrudnikov politsii Rossiiskoi Federatsii i zarubezhnykh gosudarstv // NB: Rossiiskoe politseiskoe pravo.-2013.-1.-C. 65-83. DOI: 10.7256/2306-4218.2013.1.735. URL: http://www.e-notabene.ru/pm/article_735.html 